\title{
The prevalence of psychiatric comorbid disorders among children with specific learning disorders: a systematic review
}

\author{
Mona Sameeh Khodeir ${ }^{1^{*}}$ D, Safaa Refaat El-Sady ${ }^{1}$ and Huda Abd El-Razek Mohammed²
}

\begin{abstract}
Background: Understanding comorbidity of psychiatric disorders with specific learning disorders (SLD) is important because the presence of any additional disorder to the learning disability may affect the severity and prognosis of the SLD symptoms and requires specific treatments and interventions.

Main body of the abstract: The purpose of this systematic review was to describe the prevalence of comorbid psychiatric disorders among children with SLD between 6 and 18 years. English studies published between 2013 and 2018 were located through searches of PubMed and ScienceDirect. In this review, only 5 articles met the inclusion criteria. The quality of the included studies was assessed with the Cochrane risk of the bias assessment tool. The prevalence of ADHD and anxiety disorder was reported in 4 studies. Prevalence of conduct disorder (CD) and depression was reported by 3 studies, and 2 studies reported the prevalence of oppositional defined disorders $(\mathrm{ODD})$. Although this review included a small number of studies that used a diversity of methods to diagnose psychiatric disorders, the results of the prevalence rates were homogenous.
\end{abstract}

Short conclusion: The included studies reported that ADHD had the highest prevalence rate among children with SLD followed by anxiety and depressive disorders. Both CD and ODD were the least prevalent and are linked to the existence of ADHD. Further worldwide future studies are needed to estimate the prevalence rate of such psychiatric disorders among children with SLD, taking into consideration the use of agreed assessment methods for diagnosing the psychiatric disorders and the SLD.

Keywords: Prevalence of psychiatric disorders, Co-morbidity, Specific learning disorders, Learning disability

\section{Background}

Literature reported the co-existence of psychiatric disorders among some children with specific learning disorders. The presence of such comorbidity at the same time has its negative impacts on the children as regards his/ her learning and educational abilities and his/her social life. Together, it worsens the clinical picture and the prognosis of the associated psychiatric disorder, as well as the SLD. Therefore, estimating the prevalence of

\footnotetext{
*Correspondence: mona.khodeir@med.asu.edu.eg;

dr.mona.khodair@gmail.com

${ }^{1}$ Unit of Phoniatrics, Otorhinolaryngology Department, Faculty of Medicine, Ain Shams University, Abbassia, Lotfy Elsayed street, Cairo 11566, Egypt Full list of author information is available at the end of the article
}

psychiatric disorders comorbid with SLD disease is very important as it provides physicians information about the burden of these disorders and helps them identifying them early and preventing its impact on the child.

\section{Main text}

Specific learning disorders (SLD) are one of the most significant disorders facing school-age children. According to the American Psychiatric Association" APA" [1], the prevalence of SLD is $5-15 \%$ among the school-age children across different languages and cultures. SLD was previously known as a learning disorder, and it is included a heterogeneous group of disorders manifested by significant difficulties in the acquisition and use of reading (dyslexia), writing

\section{Springer Open}

(๑) The Author(s). 2020 Open Access This article is licensed under a Creative Commons Attribution 4.0 International License, which permits use, sharing, adaptation, distribution and reproduction in any medium or format, as long as you give appropriate credit to the original author(s) and the source, provide a link to the Creative Commons licence, and indicate if changes were made. The images or other third party material in this article are included in the article's Creative Commons licence, unless indicated otherwise in a credit line to the material. If material is not included in the article's Creative Commons licence and your intended use is not permitted by statutory regulation or exceeds the permitted use, you will need to obtain permission directly from the copyright holder. To view a copy of this licence, visit http://creativecommons.org/licenses/by/4.0/. 
(dysgraphia), or mathematical (dyscalculia) abilities despite intact senses, normal intelligence, proper motivation, and adequate sociocultural opportunity. Recently, the authors consider SLD as a neurodevelopmental disorder with a biological origin including the interaction of genetic, epigenetic, and environmental factors that affect the brain's ability to perceive and/or process verbal and non-verbal information efficiently and accurately.

SLD commonly co-occurred with other neurodevelopmental and mental disorders with psychiatric disorders being the commonest comorbid disorders among the SLD children [2, 3]. Many studies reported the existence of some internalizing and externalizing psychiatric disorders in children with SLD [4]. Among the externalizing psychiatric disorders, a strong relationship between ADHD and reading disabilities was found [5]. Conduct disorder (CD) was present five times more often in children with SLD [6]. Although the literature reported few data concerning the association between SLD and internalizing disorders, the latest studies have found a greater incidence of internalizing symptoms with anxiety and depressive disorders on the top [7]. These psychiatric co-morbidities with SLD are either a direct consequence of the same deficits in the central processing patterns that generate the learning problems or a cause of frustration and failure in academic achievement. These difficulties are claimed to move a vicious circle that leads the child towards ever-greater cognitive and social-emotional impoverishment.

For phoniatricians and speech-language therapists, it is important to understand and detect the prevalence of the existence of psychiatric co-morbidity with learningdisabled children. This is because the presence of any additional disorder, besides the learning difficulties, will affect the severity of the clinical picture of SLD and consequently its prognosis [8]. Moreover, rehabilitation of learning-disabled children with psychiatric co-morbidity needs the contribution of the psychiatrists in hands with the phoniatricians and speech-language therapists. Those children need behavioral and psychological plans in addition to specific rehabilitation programs that target their learning problems [9].

In this systematic review, the prevalence studies on psychiatric co-morbidity in children with specific learning disorders were evaluated and we highlighted the differences and possible explanations for the variations among them. This will guide us in estimating the size of this problem, thus, to be considered in the assessment protocols and the rehabilitation program of such children with SLD.

\section{Method}

The systematic review was carried out according to the guidelines of the PRISMA-DTA protocol for systematic reviews and meta-analysis [10].

\section{Eligibility criteria-study selection}

Studies selected for the current systematic review were observational cross-sectional, case-control, and cohort studies in the English language that study the prevalence of psychiatric co-morbidity in children with SLD. The studies selected were conducted at governmental or nongovernmental schools, hospitals, or institutes in the duration from 2013 to 2018. The studies selected met the following selection criteria: participants in each study were children in the age range between 6 and 18 years old, had an average intelligence quotient or above according to Wechsler Intelligence Scale for Children [11] or its revised versions [12] or any of its translated versions, and with no past or present history of any neurological problems and peripheral hearing and/or visual sensory impairment. The diagnosis of SLD among the participated children in the selected studies should be done by standardized and validated measures (tests, scales, and batteries). Taking into consideration that these measures could differ from country to country to suit the children's mother language and culture in every country.

Also, the studies selected focused on measuring the prevalence of the following psychiatric disorders: ADHD, conduct disorder (CD), oppositional defiant disorder (ODD), depression, and anxiety disorders (AD) in children with SLD. Measures used to diagnose the presence of these psychiatric disorders are (1) Developmental Psychopathology Checklist for Children (DPCL) [13], (2) the Diagnostic and Statistical Manual-IV Based Disruptive Behavior Disorders Screening and Rating Scale [14], (3) Children's Depression Inventory (CDI) [15], (4) Conners' Teacher Rating Scale [16], (5) Diagnostic Interview Schedule for Children, Version IV (DISC) [17], and (6) Mini International Neuropsychiatric Interview Kid (MINI Kid) [18]. Children who participated in each of the studies selected did not receive any medical treatment for the psychiatric disorder they had.

\section{Literature selection-search strategy}

Two authors performed independent searches of systematic titles and abstracts based on the selection criteria. Studies were conducted up and located through electronic searches for studies in the English language in two databases: (1) PubMed and (2) ScienceDirect, starting in December 2017. A search strategy was developed by establishing a matrix of synonyms to cover all possible terms indicating specific learning disabilities. The included terms of prevalence, SLD, and psychiatric co-morbidity were the principal factors in this systematic review.

During the search, the search limitations of the PubMed and ScienceDirect were used including articles' language, age of participants, and publication date. Studies that were irrelevant in the early stages of the search on the bases of titles presented in the electronic searches were excluded. Studies that seemed eligible from their title or abstract were 
obtained in full text and underwent further inspection based on the eligibility criteria. Monthly search updates were done to check for additional article inclusions, and this resulted in no additional article inclusion up to date. Any discrepancy between the two authors was solved through discussion meetings, and a third author was consulted if necessary.

\section{Data extraction and analysis}

Two authors collected independently the following information from the recruited studies: the study's authors, publication year, country, study design, sample size, participants' ages, tools used to diagnose the SLD, and the scope of the study. Data related to the prevalence rate of psychiatric disorders ADHD, anxiety, CD, ODD, and depression or its calculation from the included articles were also extracted.

\section{Quality or risk of bias assessment}

Two review authors independently assessed the methodological quality using the Cochrane Risk of Bias Assessment Tool that included a description and a judgment (low risk of bias, high risk of bias, or unclear risk of bias) for the following domains for each of the included studies: (1) selection bias, (2) detection bias, (3) attrition bias, and (4) reporting bias. "Low risk of bias" was given to the articles which were thoroughly discussing this article concerning the specific bias. "Unclear risk of bias" was given to those who were not specifically stating how the bias affected their results, but where we, as readers, could evaluate this by interpreting text and data. "High risk of bias" was given to the articles where an evaluation of the bias could not be made sufficiently.

\section{Results}

\section{Results of literature search}

Initially, the search strategy yielded 593 studies. After the removal of duplicates, 519 studies remained for further screening. Based on title and abstract screening, 501 more were removed, and the result was 18 potentially eligible studies. After full-text reading, another 13 studies were excluded. Reasons for exclusion were different study designs (3 studies), studies did not define the exact method used in diagnosing the psychiatric disorders (9 studies), and the study was not in the English language (1 study) (Fig. 1).

\section{Study characteristics Study design}

Five studies fulfilled all the inclusion criteria [2, 8, 1921] (Table 1). Four out of the recruited studies were case-control studies $[2,8,20,21]$, while only one study by Altay and Görker [19] was a cross-sectional study.

\section{Participants characteristics}

The 5 included studies involved together 1112 children; 650 children were diagnosed as SLD and the remaining 462 were control groups with a typical academic achievement. The mean age of SLD children and the control groups were between 6 and 18 years. Of the SLD children group, 196 were females and 454 were males. The SLD children were diagnosed with at least one of these psychiatric comorbid disorders: ADHD, CD, ODD, depression, and/or anxiety disorders (AD).

\section{Characteristics of the tools used to diagnose the SLD}

The recruited studies differed in the tools they used in diagnosing the SLD. However, 2 studies $[8,19]$ made their diagnosis based on the diagnostic criteria of the Diagnostic and Statistical Manual of Mental Disorders Fourth Edition Text Revision "DSM-IV TR" [22] and Fifth Edition "DSM-V" [1] respectively. These 2 studies also supported the diagnosis of SLD by other tests. Margari et al. [8] assessed the academic achievement using the following: (1) MT Group Reading Tests for Primary School [23], (2) MT Group Reading Tests for Middle School [24], (3) MT Group Advanced Reading and Mathematics Tests for the first biennium of Secondary School [25], (4) Battery for the Evaluation of Developmental Dyslexia and Dysorthography for Primary and Middle school [26], (5) Evaluation Tests of Calculation Ability for Primary School [27], and (6) Evaluation Tests of Calculation Ability and Problem Solving for Middle School [28], while Altay and Görker [19] used the Specific Learning Difficulties Symptom Scale which is completed by both parents and teachers and the ReadingWriting-Mathematics Skills Evaluation List (Error Analysis) to identify the areas of difficulty in reading, writing, and/or mathematics [29].

Thakkar et al. [20] used the curriculum-based evaluation to diagnose SLD. This curriculum employs a locally developed and validated English curriculum-based test and assesses specific areas of learning (basic learning skills, reading and listening comprehension, oral and written expression, and mathematical calculation and resonating) [30-32].

Bandla et al. [2] used a checklist developed by the Department of Psychiatry, B. Y. L. Nair Hospital, and T. N. Medical College to identify learning disabilities and confirm the diagnosis of SLD by applying the NIMHANS SLD index of Specific Learning Disabilities [33].

Lastly, Törő et al. [21] used the Dyslexia Differential Diagnosis Maastricht-Hungarian Standard Test computerized dyslexia battery "3DM-H" [34]. The "3DM- $\mathrm{H}$ " is the Hungarian standardized adaptation of the Dutch 3DM dyslexia battery developed by Blomert and Vaessen [35]. 


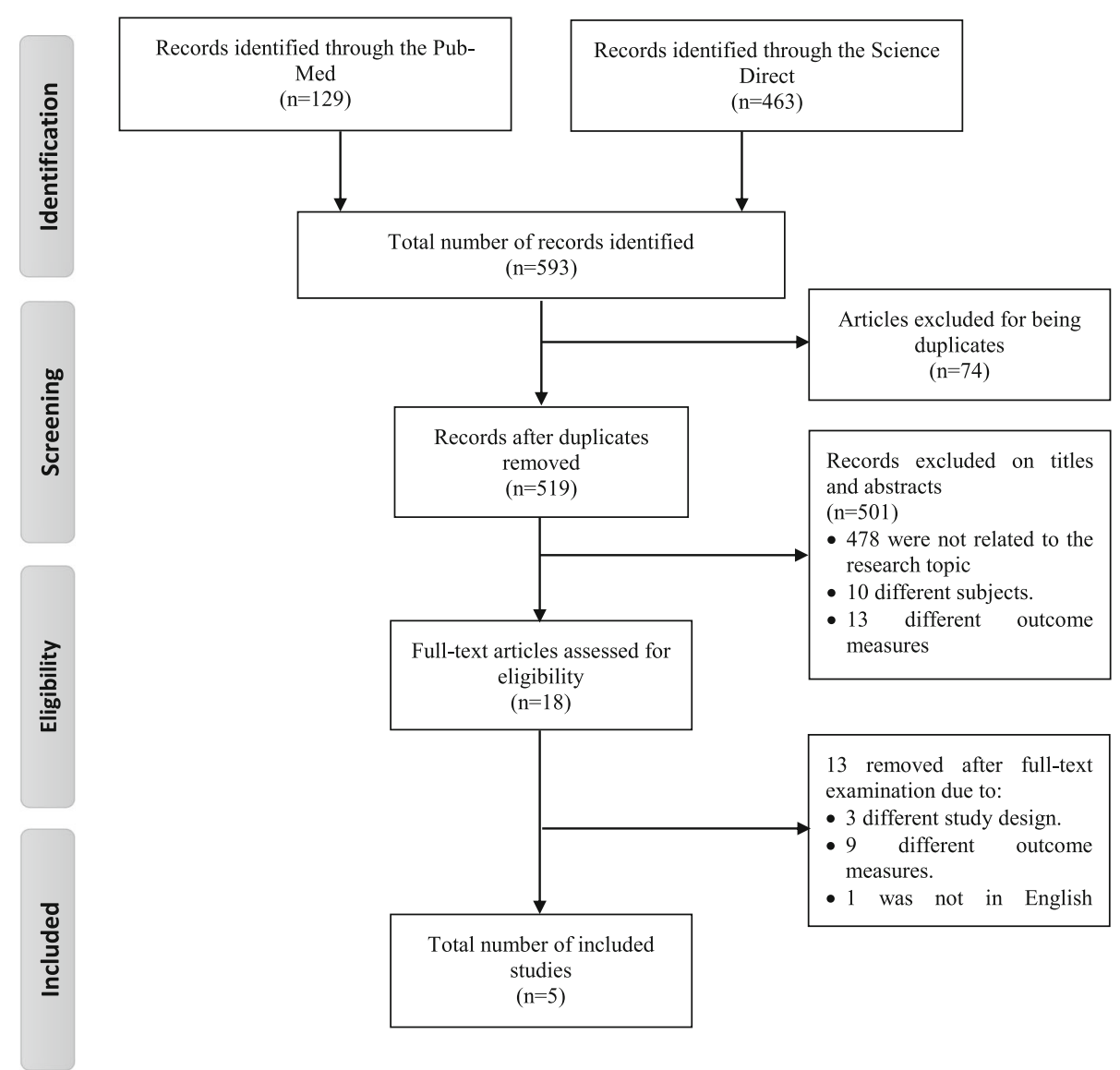

Fig. 1 Flow chart of the included and excluded studies

\section{Characteristics of the tools used to diagnose psychiatric disorders}

The tools used in the recruited studies to diagnose the psychiatric disorders in children with SLD varied according to the study country and settings (Table 2).

Margari et al. [8] used the following measures for psychopathological evaluation: (1) Child Behavior Checklist (CBCL), which is a widely used caregiver report form identifying behavior problems in children, (2) Kiddie Schedule for Affective Disorders and Schizophrenia for School-Age Children-Present and Lifetime Version (K-SADS) [36], which is a semi-structured interview aimed at early diagnosis of affective disorders such as depression, bipolar disorder, and anxiety disorders, (3) Children Depression Inventory (CDI) [15], which is a psychological assessment that rates the severity of symptoms related to depression or dysthymic disorder in children and adolescents, and (4) Conner's Parent Rating Scale-Revised-Long Version [16], which is a parentreport or teacher-report inventory consisting of 18 questions regarding a child's behavior over the past 6 months.

Thakkar et al. [20] used the Spence Children's Anxiety Scale (SCAS) [37] child self-report version questionnaire for anxiety symptoms which is a widely used self-report questionnaire to assess children and adolescents' perceptions of the frequency with which they experience symptoms relating to separation anxiety, social anxiety obsessions/compulsions, panic/agoraphobia, fears of physical injury, and generalized anxiety and is based on the DSM-IV diagnostic categories of anxiety disorders.

Bandla et al. [2] used the Developmental Psychopathology Checklist for Children (DPCL) [13] which is a screening tool to assess psychopathology in children. The tool covers developmental history, developmental problems, psychopathology, psychosocial factors, temperamental profile, and social supports and assets.

Altay and Görker [19] used the Kiddie Schedule for Affective Disorders and Schizophrenia Scale for SchoolAge Children-Present and Lifetime Turkish Adaptation (K-SADS) [36] used to present and lifetime psychopathologies in children and adolescent and the Child and Adolescent Disruptive Behavioral Disorders Screening and Rating Scale Based on DSM-IV [14] which is also completed by both teachers and parents to assess psychopathology in children and adolescents.

Törö et al. [21] used the modified version of the Hungarian Mini International Neuropsychiatric Interview 
Table 1 The characteristics of the included studies

\begin{tabular}{|c|c|c|c|c|}
\hline $\begin{array}{l}\text { Authors (Year), } \\
\text { Country }\end{array}$ & Number & Gender and Age & $\begin{array}{l}\text { Time of the } \\
\text { Study }\end{array}$ & Scope of the study \\
\hline $\begin{array}{l}\text { Margari et al. [8], } \\
\text { Bari, Italy }\end{array}$ & $\begin{array}{l}\text { 448, (240 with } \\
\text { SLD, } 208 \operatorname{LD~NOS}^{6} \text { ) }\end{array}$ & $\begin{array}{l}\text { The SLD children were } 184 \text { males, } \\
56 \text { females, (mean age } 10.45 \text { y). } \\
\text { The LD NOS children were } 135 \\
\text { males, } 73 \text { females, (mean age 10.2). } \\
\text { The age range for both groups was } \\
7-16 \mathrm{y} \text {. }\end{array}$ & $\begin{array}{l}\text { October } 2010 \\
\text { and December } \\
2012\end{array}$ & $\begin{array}{l}\text { To analyze comorbidities in LD, considering } \\
\text { separately the SLD and LD NOS subgroups to } \\
\text { deepen clinical and etiopathogenic knowledge } \\
\text { of these disorders and improve their treatment. }\end{array}$ \\
\hline $\begin{array}{l}\text { Thakkar et al. [20], } \\
\text { Mumbai, India }\end{array}$ & $\begin{array}{l}\text { 276, (138 SLD, } \\
\left.138 \text { Control }^{8}\right)\end{array}$ & $\begin{array}{l}\text { Both SLD \& control }{ }^{8} \text { groups had } \\
103 \text { males, } 35 \text { females, (mean age } \\
12.23 \text { y, range } 8-15 \text { y) }\end{array}$ & $\begin{array}{l}\text { March } 2011 \text { to } \\
\text { January } 2012\end{array}$ & $\begin{array}{l}\text { To determine if school students with newly } \\
\text { diagnosed SLD were more likely to have } \\
\text { anxiety than their regular peers. }\end{array}$ \\
\hline $\begin{array}{l}\text { Bandla et al. [2], } \\
\text { Hyderabad, India }\end{array}$ & $\begin{array}{l}76(62 \text { SLD } \\
\text { children, } 34 \\
\left.\text { Control }^{8}\right)\end{array}$ & $\begin{array}{l}\text { Age range } 6-12 \mathrm{y} \text { ). } \\
\text { The SLD children were } 40 \text { males, } \\
22 \text { females, (mean age } 9.28 \mathrm{y} \text { ). } \\
\text { The Control }{ }^{8} \text { were } 18 \text { males, } \\
16 \text { females, (mean age } 9.28 \mathrm{y} \text { ) }\end{array}$ & Not mentioned & $\begin{array}{l}\text { 1) To study the number of children having } \\
\text { SLDs and comorbidities in a school setting. } \\
\text { 2) To study the comorbidities in children with } \\
\text { SLDs who identified and on remedial education. } \\
\text { 3) To study the comorbidities in children who } \\
\text { do not have SLDs } \\
\text { 4) To study the difference in sociodemographic } \\
\text { variables as well as a comorbidity in the } 3 \text { groups. }\end{array}$ \\
\hline $\begin{array}{l}\text { Altay \& Gorker } \\
\text { [19], Edirne, } \\
\text { Turkey }\end{array}$ & 80 with SLD & $\begin{array}{l}49 \text { males, } 31 \text { females, mean age } \\
9.0 \text { y, range } 6-15 y)\end{array}$ & $\begin{array}{l}\text { January and June } \\
2015 .\end{array}$ & $\begin{array}{l}\text { To obtain scientific data for our country (Turkey) } \\
\text { regarding SLD and the accompanying psychiatric } \\
\text { disorders and to contribute to the literature. }\end{array}$ \\
\hline $\begin{array}{l}\text { Toro et al. [21], } \\
\text { Budapest, } \\
\text { Hungary }\end{array}$ & $\begin{array}{l}212,(130 \text { with } \\
\left.\mathrm{RD}^{7}, 82 \text { Control }^{8}\right)\end{array}$ & $\begin{array}{l}\text { Age range } 7-18 \mathrm{y} \text {. } \\
\text { The RD children were } 78 \text { males, } \\
52 \text { females (mean age } 10.2 \mathrm{y} \text { ) } \\
\text { The Normal children were } 50 \\
\text { males, } 32 \text { females, (mean age } \\
9.66 \mathrm{y} \text { ) }\end{array}$ & Not mentioned & $\begin{array}{l}\text { To investigate the comorbidity of subthreshold and } \\
\text { full psychiatric disorders with RD while comparing } \\
\text { subgroups based on the age of RD recognition } \\
\text { (early vs. late) }\end{array}$ \\
\hline
\end{tabular}

Note ${ }^{1} A D H D$ Attention Deficit Hyperactive Disorder, ${ }^{2} C D$ Conduct Disorder, ${ }^{3} O D D=$ Oppositional Defiant Disorder, ${ }^{4} G A D$ Generalized anxiety Disorder, ${ }^{5} S A D$ Social Anxiety Disorder, ${ }^{6}$ LD NOS Learning Disability Not Otherwise Specified, ${ }^{7} R D$ Reading Disability (a type of SLD), ${ }^{8}$ Control Children with typical academic school performance

Kid (MINI Kid) [18] to assess psychopathology in children which is a short, comprehensive, structured diagnostic interview that assesses 25 child psychiatric disorders per the DSM-IV. This scale uses the terms full (FT) and subthreshold (ST) pictures that indicate whether the child had the full picture or some symptoms of every psychiatric disorder it includes.

\section{Results of individual studies}

The recruited studies found that psychiatric disorders are prevalent among children with SLD. This was obvious in 3 studies [2, 20,21] which compared children with SLD to a control group of children with typical school performance. Table 2 shows that among the psychiatric comorbidity with SLD, ADHD came to the first position followed respectively by anxiety disorders and depression. $\mathrm{CD}$ and ODD are the least common co-morbidity with SLD; however, their prevalence was correlated to the existence of ADHD simultaneously in children with SLD.

\section{Risk of bias and applicability}

Table 3 shows that among the 5 studies included, 4 clearly described an adequate selection process and recruitment of the participants while only one showed selection bias. The sample size calculation was unclearly described in 3 studies and not described clearly in the other 3 studies.
However, only one sample size was adequate while the other 4 studies had small size samples. All 5 studies described the assessment of outcomes clearly with the same assessment measures. No attrition bias was present in the 5 studies. No selective reporting of data was observed in any of the included studies.

\section{Discussion}

Estimating the prevalence of a disease is very important to inform researchers, physicians, and guideline developers about the burden of this disorder. Thereby, this supports the process of early identification, prevention, and treatment policy for such disorder. Also, knowing prevalence provides data on the baseline risk for a given disease in a patient group which influences effect measures. Recently, it is well recognized that there are many psychiatric disorders comorbid with SLD. The co-occurrence of these psychiatric disorders in children with SLD aggravates clinical picture and affects the prognosis of their learning disability problem. Thus, considering early assessment and treatment of these psychiatric disorders while managing children with SLD could promise a good prognosis and shorter and less costly treatment.

The purpose of this study was to describe the prevalence rate of psychiatric comorbid disorders in children with SLD. This systematic review faced many obstacles that 
Table 2 The tools used to assess the psychiatric disorders and the prevalence of the psychiatric comorbid disorder among the SLD children included in the recruited studies

\begin{tabular}{|c|c|c|c|c|c|c|c|c|c|c|c|c|}
\hline \multirow[t]{3}{*}{ Authors } & \multirow{3}{*}{\multicolumn{2}{|c|}{ Outcome Measures }} & \multicolumn{10}{|c|}{ Prevalence of the Psychiatric Comorbid Disorder (\%) } \\
\hline & & & \multicolumn{3}{|l|}{ ADHD } & \multirow[t]{2}{*}{ CD } & \multirow[t]{2}{*}{ ODD } & \multicolumn{4}{|c|}{ Anxiety Disorder } & \multirow[t]{2}{*}{ Depression } \\
\hline & & & Inattentive & $\begin{array}{l}\text { Hyperactive } \\
\text { Impulsive }\end{array}$ & Combined & & & Generalized & Social & Separation & $\begin{array}{l}\text { Specific } \\
\text { phobia }\end{array}$ & \\
\hline $\begin{array}{l}\text { Margari } \\
\text { et al. [8] }\end{array}$ & \multicolumn{2}{|c|}{$\begin{array}{l}\cdot \mathrm{CBCL}^{1} \\
\cdot{\mathrm{K}-S A D S^{2}}^{2} \\
\cdot \mathrm{CDI}^{3} \\
\cdot \text { Conner's Parent } \\
\text { Rating Scale - ADHD. }\end{array}$} & $\begin{array}{l}\text { SLD: } 33 \\
\text { LD NOS: } 25.4\end{array}$ & & & - & - & $\begin{array}{l}\text { SLD: } 28.8 \\
\text { LD NOS:16.4 }\end{array}$ & & & & $\begin{array}{l}\text { SLD: } 9.4 \\
\text { LD NOS: } \\
2.1 \%\end{array}$ \\
\hline $\begin{array}{l}\text { Thakkar } \\
\text { et al. [20] }\end{array}$ & \multicolumn{2}{|l|}{$\mathrm{SCAS}^{4}$} & - & - & - & - & - & $\begin{array}{l}\text { SLD: } 24.64 \\
\text { Control: } 4.35\end{array}$ & & & & - \\
\hline $\begin{array}{l}\text { Bandla } \\
\text { et al. [2] }\end{array}$ & \multicolumn{2}{|l|}{$\mathrm{DPCL}^{5}$} & SLD: 41.9 & & & SLD: 3 & - & - & & & & - \\
\hline \multirow{2}{*}{$\begin{array}{l}\text { Altay \& } \\
\text { Gorker } \\
\text { [19] }\end{array}$} & \multirow{2}{*}{\multicolumn{2}{|c|}{$\begin{array}{l}\text { - DSM-IV for ADHD, } \\
\text { CD and ODD. } \\
\text { - K-SADS (Turkish } \\
\text { version) }\end{array}$}} & Total $=82.3$ & & & 16.3 & 26.3 & Total $=68.8$ & & & & 8.8 \\
\hline & & & 38.8 & 2.5 & 40 & & & 5 & 5 & 12.5 & 46.3 & \\
\hline \multirow{9}{*}{$\begin{array}{l}\text { Toro et } \\
\text { al. [21] }\end{array}$} & \multicolumn{12}{|l|}{ MINI Kid ${ }^{6}$} \\
\hline & \multirow{4}{*}{$\begin{array}{l}\text { Disorder } \\
\text { Full picture }\end{array}$} & $\mathrm{RD}^{7}$ & 25.4 & & & 0.8 & 7.8 & Total $=28.6$ & & & & 10.8 \\
\hline & & & & & & & & 5.4 & 0.8 & 16.2 & 6.2 & \\
\hline & & Control $^{8}$ & 8.5 & & & 0 & 3.7 & Total $=13.4$ & & & & 8.6 \\
\hline & & & & & & & & 3.7 & 2.4 & 7.3 & 0 & \\
\hline & \multirow{4}{*}{$\begin{array}{l}\text { Disorder } \\
\text { Sub- } \\
\text { threshold } \\
\text { picture }\end{array}$} & $\mathrm{RD}^{7}$ & 35.4 & & & 10 & 12.3 & Total $=69.2$ & & & & 8.4 \\
\hline & & & & & & & & 6.9 & 16.2 & 23.8 & 22.3 & \\
\hline & & Control $^{8}$ & 36.6 & & & 24 & 22 & Total $=43.8$ & & & & 1.2 \\
\hline & & & & & & & & 4.9 & 8.5 & 13.3 & 17.1 & \\
\hline
\end{tabular}

Note ${ }^{1}$ CBCL Child Behavior Checklist, ${ }^{2}$ K-SADS Kiddies Schedule for Affective Disorders and Schizophrenia for School-Age Children - Present and Lifetime Version, ${ }^{3} \mathrm{CDI}$ Children Depression Inventory, ${ }^{4}$ SCAS Spence Children's Anxiety Scale, ${ }^{5}$ DPCL Developmental psychopathology checklist for children, ${ }^{6}$ Mini International Neuropsychiatric Interview Kid, ${ }^{7}$ RD Reading Disability (a type of SLD), ${ }^{8}$ Control Children with typical academic school performance

made a difficulty to analyze statistically the results of the included studies. Firstly, only 5 articles that provided a prevalence rate of 5 psychiatric disorders in children diagnosed with SLD were reached. This is because while reviewing the literature, most searched studies analyzed multiple categories of disabilities under the title of learning disorder/disabilities such as intellectual disability, autism spectrum disorders, hearing/visual impairments, and traumatic brain injury. These articles were all excluded because this review meant children who have learning problems despite intact senses, normal intelligence, proper motivation, and adequate sociocultural opportunity, which is recently called by the American Psychiatry Association [1] specific learning disorders (SLD). Adding to that are the small sample size in most of the studies and the diversity of the assessment methods used to diagnose SLD and the psychiatric disorders among the included studies. This small number of the included articles was an obstacle against reaching an exact

Table 3 Risk of bias summary: review authors' judgments about each risk of bias item for each included study

\begin{tabular}{|c|c|c|c|c|c|c|c|}
\hline \multirow[t]{2}{*}{ Authors } & \multirow[t]{2}{*}{$\begin{array}{l}\text { Selection } \\
\text { bias }\end{array}$} & \multirow{2}{*}{$\begin{array}{l}\text { Sample } \\
\text { size } \\
\text { bias }\end{array}$} & \multirow{2}{*}{$\begin{array}{l}\text { Detection } \\
\text { bias } \\
\text { (Assessment } \\
\text { of outcome) }\end{array}$} & \multirow{2}{*}{$\begin{array}{l}\text { Attrition } \\
\text { bias } \\
\text { (Incomplete } \\
\text { outcome } \\
\text { data } \\
\text { addressed) }\end{array}$} & \multicolumn{3}{|c|}{$\begin{array}{l}\text { Reporting bias } \\
\text { (Free of selective reporting) }\end{array}$} \\
\hline & & & & & Recall bias & $\begin{array}{l}\text { Information or Miss } \\
\text { classification bias }\end{array}$ & Assessment of exposure \\
\hline Margari et al. [8] & + & $\mathrm{O}$ & + & + & + & + & + \\
\hline Thakkar et al. [20] & + & $\mathrm{O}$ & + & + & + & + & + \\
\hline Bandla et al. [2] & + & - & + & + & + & + & + \\
\hline Altay \& Gorker [19] & - & - & + & + & + & + & + \\
\hline Toro et al. [21] & + & $\mathrm{O}$ & + & + & + & + & + \\
\hline
\end{tabular}


prevalence rate for each of the included psychiatric disorders.

The recruited studies showed prevalence rates for all the psychiatric disorders to a greater extent near to each other except the study by Altay and Görker [19]. This study recorded the largest prevalence rates for all the psychiatric co-morbidity with SLD over the other recruited studies. This may be due to the smaller sample size ( 80 children) of the study, which was not suitable for statistical comparison, and this was admitted by Altay and Görker themselves as one of the limitations of their study. Furthermore, the authors mentioned that they included in their study children diagnosed with SLD and having no "severe" hearing and/or visual defects. The authors did not clarify whether they included SLD children with mild or moderate degrees of hearing/visual defects that might cause pollution of their sample and bias of their results, as children with such defects are not defined to have SLD as delineated by the American Psychiatric Association [1, 22] even if they have learning problems. The learning problems they might have are a direct consequence of their hearing and/or visual impairment or their psychiatric and intellectual disability. Those children should not be confused with SLD children who according to Felder et al. [38] have learning problems despite intact senses, normal intelligence, proper motivation, and adequate sociocultural opportunity. Adding to that, Altay and Görker depended on diagnosing SLD on a standardized SLD scale that was completed by the teachers and the role of the clinicians was just assessing children's learning performance by direct observation and clinical examination of the children without conducting any comprehensive assessment to establish the diagnosis of SLD. Thus, this added to the bias of the sample included and in turn affected the prevalence results of this study.

This systematic review revealed that among the recruited studies, ADHD was the most prevalent, and this matches with reports by the American Psychiatric Association in its DSM-V [14]. This current study found that the prevalence rate of ADHD with SLD was ranging from 12.3 to $82.3 \%$. Thus, after reconsidering the results by Altay and Gorker, the prevalence rate varies from 25.5 to $41.9 \%$. This goes with many studies that documented the association between SLD and ADHD. These 2 disorders recorded an association rate of 10 to $60 \%$ and 18 to $60 \%$ by Beitchman et al. [39] and DuPaul et al. [40] respectively.

The association between SLD and ADHD has many explanations; however, there is no clarification whether which of them begins firstly. The link between both SLD and ADHD could be explained by the strong genetic predisposition between both with many affected genes shared between them as mentioned by Al-Mamari et al. [41] Besides that, it is obvious that children with SLD have 2 main deficits that affect the learning process, namely problems in attention and memory deficits especially that affecting the working memory (WM). Undoubtedly, attention is one of the most important attributes in the learning process that enables the child to maintain his/her focus even when there are distractions in the environment or the thoughts. Attention cooperates also with the memory for better storage of the newly learned information and a major problem that interferes with the learning process of children is their difficulty in paying attention [42]. Eventually, working memory is the key role of the learning process with all its stages, information input, processing, storage, and retrieval. Working memory helps children to pay attention, remember instruction, and accesses information although the classroom $[43,44]$.

Since, ADHD is primarily a disorder of inattention, hyperactivity, and impulsivity, deficits in the attention that will affect the child's ability to study and memorize school lessons. Together with the hyperactive/impulsive behaviors, it will increase the child's distractibility and make him/her unable to focus attention on what is on his/her hands and in turn will affect his/her classroom interaction and academic achievement. Thus, ADHD, as an independent disorder, causes significant problems with the academic and social experiences of school-aged children [45].

Besides, and as recently proved, ADHD is considered as an executive function disorder affecting the 3 main executive brain processes, working memory, cognitive flexibility, and inhibitory control. The variation in the 3 symptoms of ADHD (inattentive, hyperactivity, impulsivity) among children, hence, depends upon which of these 3 processes are most/least impaired [46].

This could be another explanation of the relationship between SLD and ADHD that deficits in working memory are accused in both ADHD and SLD. Working memory is the key role of the learning process with all its stages, information input, processing, storage, and retrieval. This gives way to conclude that whenever WM is affected, the risk to have ADHD and SLD together increases, and this explains the association between both too.

Afterward, anxiety disorders were found to be the second prevalent psychiatric comorbid disorder with SLD among the recruited studies. Its prevalence rate was ranged from 24.64 to $28.8 \%$. Many studies suggested the relationship between SLD and anxiety disorders and reported higher prevalence and incidence rates of anxiety disorders with SLD [7]. A meta-analysis by Nelson and Harwood [47] that involved 58 studies found higher anxiety scores in children with SLD in $95 \%$ of the studies. Some authors claimed the link between anxiety disorders and SLD is bi-directional [48]. Children with SLD will develop anxiety disorders secondary to their academic failures. Moreover, anxiety could be the primary disorder affecting students and reflected negatively on their academic performance. 
Whether anxiety is the primary or the secondary disorder, its negative effect on the learning process at all its stages could not be ignored. Anxiety introduces taskirrelevant cognitions into the limited storage component of the information processing system. The anxietyproduced distracting information disrupts the attentional focus and consumes space in the working memory, resulting in inefficient information processing [49]. Besides, individuals showing high levels of anxiety engage metacognitive skills (e.g., strategy use and monitoring) less frequently. This impairment of metacognition and working memory as mentioned by Pekrun et al. [50] due to anxiety adds to the already present impairment of them in the learning-disabled children.

Furthermore, academic achievement is a central activity of childhood with adequate progress in reading, writing, and mathematics which represents one of the major developmental tasks to be accomplished during the school-age years. So, children who struggle to master academic skills develop an anxiety reaction in anticipation of possible academic failure they suffer from. This was evident and consistent with the results of studies by Nelson and Harwood [47] and Nelson and Gregg [51] who thought anxiety to be secondary to learning disabilities and academic failures.

Moreover, by further analysis of the prevalence rate of the subtypes of the anxiety disorders among 2 of the recruited studies $[19,21]$, it was found that the most prevalent anxiety subtype with SLD was the specific phobia (specifically school phobia) as in Altay and Görker [19], followed by a separation anxiety disorder in Törő et al. [21], and the generalized anxiety disorder was the least prevalent. This indicates that anxiety disorder in those children either school phobia or separation anxiety was the primary disorder. Those children had a great worry about being separated from his/her caregivers with an excessive and irrational fear of school and its activities, like being afraid of teachers, and are excessively self-conscious. These all will make it difficult for them to participate in class and socialize with peers and turns their school time to be harder with a great impact on their learning processes.

This study found that the prevalence of depression was ranging between 8.8 and $10.8 \%$ among children with SLD. These findings were consistent with the hypothesis that children with SLD would record higher rates of depression than children without SLD. These findings were in line with those of Willcutt and Pennington [7] who addressed that the depressed mood could negatively impact the learning process, and alternatively, children with SLD may develop mood problems as an adverse academic experience. This could be explained by the fact that children with depression may be unable to complete tasks that require high-motor and cognitive skills. They may feel confused, scatterbrained, overwhelmed, or easily frustrated and even basic everyday tasks become difficult for them to accomplish. Further, depression, as a mental health issue, impairs cognitive functioning by interfering with healthy thought processes and impacts a person's ability to concentrate and make decisions. Depression also changes the brain chemicals and electricity in a way that affects memory [52]. Memory problems and trouble remembering events or details are of the common manifestations of depression that are frequently experienced by many children, as well as adults with depression. Mood disorders affect attention and increase distractibility; furthermore, individuals with mood swings could not bother learning new things as an effect of their feelings of hopelessness or low self-esteem. Depression affects also sleep and then insomnia and hypersomnia can further impact mental health and function [53].

Concerning the co-morbidity of $\mathrm{CD}$ and ODD with SLD, studies involved in this systematic review declared that the prevalence rate of both disorders is not high with SLD. The prevalence rate of CD estimated to be $0.8-3 \%$, while the ODD prevalence rate with SLD was $7.8 \%$. The recruited studies explained the co-morbidity of both ODD and CD with SLD through their relationship with the ADHD in the first place and that it is not a direct relation to SLD. In other words, CD and ODD are comorbid disorders with SLD in children with ADHD too. This suggested that ADHD is an important factor in the development of $\mathrm{CD}$ and $\mathrm{ODD}$ as proclaimed by Huc-Chabrolle et al. [54] and Smith and Adams [55]. The explanation is that the 3 disorders (ADHD, CD, ODD) are categorized by the psychiatrists into the same psychiatric disorder which is the disruptive behavior disorder. Adding to this and from the psychiatric point of view, $\mathrm{CD}$ and $\mathrm{ODD}$ are considered a late deteriorated stage of untreated ADHD [55]. Moreover, it was found by Waldman et al. [56] that there is a genetic correlation between the 3 disorders with a shared set of genes that influence them.

Finally, the recruited studies declared that learning difficulties in SLD children accompanied by ADHD are more severe and are accompanied by more psychiatric problems, especially CD, ODD, anxiety, or depression. This goes with the results of Levy et al. [57] and was mentioned by Mugnaini et al. [58] and DuPaul et al. [40], who added that the prognosis of SLD and ADHD when accompanying each other is negatively affected. Besides that, Levy et al. [57] mentioned that reading problem scores were higher for children with both ADHD and depression or anxiety disorder symptoms and have extended this finding to combinations of two or more comorbid symptoms. The association of SLD with ADHD and another mental health disorder could be explained by the bi-directional relationship between ADHD and SLD that indicates whether the ADHD or SLD is the primary or the secondary deficit; both could share the same co-morbidity. 


\section{Conclusion}

Overall, the findings of the studies reviewed in this systematic review described that there is a higher prevalence rate of some psychiatric disorders affecting children with SLD. ADHD was the most prevalent psychiatric comorbidity in most of the studies followed by anxiety disorders, depression, ODD, and CD. ADHD with SLD is difficult to manage, and both would worsen the prognosis of each other. All the reviewed studies demonstrated the importance of recognizing and providing appropriate therapy for such disorders while managing children with SLD. Thus, screening and early detection of the psychiatric comorbidity in children with specific learning disorders should be considered and scheduled through the ordinary assessment protocols of SLD.

\section{Abbreviations}

SLD: Specific learning disorders; ADHD: Attention-deficit hyperactive disorder; CD: Conduct disorder; ODD: Oppositional defiant disorder; AD: Anxiety disorders; DSM: Diagnostic and statistical manual of disorders

\section{Acknowledgements}

Not applicable.

Ethical approval and consent to participate

Not applicable

\section{Authors' contributions}

MK and HM performed the independent systematic titles and abstracts search based on the selection criteria, collected independently the study data, and analyzed these data. SE and MK independently assessed the risk of bias of the recruited studies and interpreted the data. MK was a major contributor in writing the manuscript. All the authors read and approved the final manuscript.

\section{Funding}

This study did not receive any funds.

\section{Availability of data and materials}

The datasets used and/or analyzed during the current study are available from the corresponding author on reasonable request.

\section{Consent for publication}

Not applicable

\section{Competing interests}

The authors declare that they have no competing interests.

\section{Author details}

${ }^{1}$ Unit of Phoniatrics, Otorhinolaryngology Department, Faculty of Medicine, Ain Shams University, Abbassia, Lotfy Elsayed street, Cairo 11566, Egypt. ${ }^{2}$ Phoniatrics Unit, Otorhinolaryngology Department, Hearing and Speech Institute - Imbaba, Cairo, Egypt.

Received: 13 June 2020 Accepted: 6 November 2020

Published online: 03 December 2020

\section{References}

1. American Psychiatric Association "APA" (2013) Diagnostic and statistical manual of mental disorders 5th edition (DSM-V). American Psychiatric Association, Washington, DC

2. Bandla S, Mandadi GD, Bhogaraju A (2017) Specific learning disabilities and psychiatric co-morbidity in school children in South India. Indian J Psychol Med 39(1):76-82 https://doi.org/10.4103/0253-7176.198950

3. Sahoo MK, Biswas H, Padhy SK (2015) Psychological comorbidity in children with specific learning disorders. J Family Med Prim Care 4(1):21-25 https:// doi.org/10.4103/2249-4863.152243
4. Achenbach TM, Dumenci $L$, Rescorla LA (2001) Ratings of relations between DSM-IV diagnostic categories and items of the CBCL/6-18, TRF, and YSR. The University of Vermont, Burlington

5. Karande S, Satam N, Kulkarni M, Sholapurwala R, Chitre A, Shah N (2007) Clinical and, psychoeducational profile of children with specific learning disability and co-occurring attention-deficit hyperactivity disorder. Indian J Med Sci 61(12):639-647

6. Maughan B, Rutter M, Hagell A, Yule W (1996) Reading problems and antisocial behavior; developmental trends in comorbidity. J Child Psychol Psychiatry 37(4):405-418 https://doi.org/10.1111/j.1469-7610.1996.tb01421.x

7. Willcutt EG, Pennington BF (2000) Psychiatric comorbidity in children and adolescents with reading disability. J Child Psychol Psychiatry 41(8):10391048 https://doi.org/10.1111/1469-7610.00691

8. Margari L, Buttiglione M, Craig F, Cristella A, de Giambattista C, Matera E, Operto F, Simone M (2013) Neuro-psychopathological co-morbidity in learning disorders. BMC Neurology 13:198 https://doi.org/10.1186/14712377-13-198

9. Beitchman JH, Young AR (1997) Learning disorders with a special emphasis on reading disorders: a review of the past 10 years. J Am Acad Child Adolesc Psychiatry 36(8):1020-1032 https://doi.org/10.1097/00004583199708000-00009

10. Mclnnes MDF, Moher D, Thombs BD, McGrath TA, Bossuyt PM (2018) Preferred reporting items for a systematic review and meta-analysis of diagnostic test accuracy studies: the PRISMA-DTA statement. JAMA 31(4): 427-443 https://doi.org/10.1001/jama.2017.19163

11. Wechsler D (1949) Wechsler Intelligence Scale for Children; manual. The Psychological Corp, Oxford

12. Wechsler D (1947) Manual for the Wechsler intelligence scale for children, revised. The Psychological Corp, Oxford

13. Kapur M, Barnabas IP, Reddy MV, Rozario J, Uma H (2011) Developmental psychopathology checklist for children (DPCL). In: Hirisave U, Oommen A, Kapur M (eds) Psychological assessment of children in the clinical setting, 3rd edn. National Institute of Mental Health \& Neurosciences, Bangalore

14. American Psychiatric Association "APA" (1994) Diagnostic and statistical manual of mental disorders 4th edition (DSM-IV). American Psychiatric Association, Washington, DC

15. Kovacs M (1992) Children's depression inventory: manual. Multi-Health Systems, North Tonawanda

16. Conners CK (1969) A teacher rating scale for use in drug studies with children. Am J Psychiatry 126(6):884-888 https://doi.org/10.1176/ajp.126.6.884

17. Steenhuis MP, Serra M, Minderaa RB, Hartman CA (2009) An internet version of the diagnostic interview schedule for children (DISC-IV): correspondence of the ADHD section with the paper-and-pencil version. J Psychol Assess 21(2):231-234 https://doi.org/10.1037/a0015925

18. Sheehan DV, Sheehan KH, Shytle RD, Janavs J, Bannon Y, Rogers JE, Milo KM, Stock SL, Wilkinson B (2010) Reliability and validity of the mini international neuropsychiatric interview for children and adolescents (MINIKID). J Clin Psychiatry 71:313-326 https://doi.org/10.4088/JCP.09m05305whi

19. Altay MA, Görker I (2017) Assessment of psychiatric co-morbidity and WISC$R$ profiles in cases diagnosed with specific learning disorder according to DSM-5 criteria. Arch Neuropsychiatry J 55(2):127-134 https://doi.org/10. 5152/npa.2017.18123

20. Thakkar AN, Karande S, Bala N, Sant H, Gogtay NJ, Sholapurwala R (2016) Is anxiety more common in school students with newly diagnosed specific learning disabilities? A cross-sectional questionnaire-based study in Mumbai, Maharashtra, India. J Postgrad Med 62(1):12. https://doi.org/10.4103/2F00223859.167663

21. Törő KT, Miklósi M, Horanyi E, Kovács GP, Balázs J (2018) Reading disability spectrum: early and late recognition, subthreshold, and full comorbidity. J Learn Disabil 51(2):158-167. https://doi.org/10.1177/2F0022219417704169

22. American Psychiatric Association "APA" (2000) Diagnostic and statistical manual of mental disorders: DSM-IV-TR. American Psychiatric Association, Washington, DC

23. Cornoldi C, Colpo G (1998) Prove di lettura MT per la scuola elementare (MT Reading Tests for Elementary School-2 Second Grade). OS Special Organizations, Firenze

24. Cornoldi C, Colpo G (1995) Nuove prove di lettura MT per la scuola media inferior (Reading Test for Secondary School). Giunti O.S, Firenze

25. Cornoldi C, Pra Baldi A, Friso G, Giacomin A, Giofrè D, Zaccaria S (2010) Prove MT Avanzate di Lettura e Matematica 2 per il biennio della scuola superiore di II grado (Reading Test for High School). Giunti O.S, Firenze 
26. Sartori G, Job R, Tressoldi PE (1995) Batteria per la valutazione della dislessia e della disortografia in età evolutive (Battery for the evaluation of dyslexia and disortography in evolutionary age). Giunti Organizzazioni Speciali, Firenze

27. Cornoldi C, Lucangeli D, Bellina M (2012) AC-MT 6-11. Test di valutazione delle abilità di calcolo e soluzione dei problem [AC-MT 6-11 - Test for the evaluation of calculating and problem-solving abilities]. Gruppo MT-Erickson, Trento

28. Cornoldi C, Cazzola C (2003) Test di valutazione delle abilità di calcolo e problem solving dagli 11 ai 14 anni (Evaluation test of calculation skills and problem solving from 11 to 14 years old). Edizioni Erickson, Gardolo-Trento

29. Korkmazlar Ü (1993) Özel Öğrenme Bozukluğu: 6-11 Yaş İlkokul Çocuklarında Özel Öğrenme Bozukluğu ve Tanı Yöntemleri (Special Learning Disorder: Special Learning Disorder and Diagnostic Methods in Primary School Children 6-11 Years). Taç Ofset, İstanbul

30. Karande S, Kulkarni M (2005) Specific learning disability: the invisible handicap. Indian Pediatr 42:315-319

31. Deno SL, Fuchs LS, Marston D, Shinn J (2001) Using curriculum-based measurement to establish growth standards for students with learning disabilities. School Psych Rev 30:507-524

32. Sholapurwala RF (2010) Curriculum-based test for the educational evaluation of learning disability, 1st edn. Jenaz Printers, Mumbai

33. Hirisave U, Oommen A, Kapur M (2006) Psychological assessment of children in the clinical setting. NIMHANS Index of Specific Learning Disabilities Samudra Offset Printers, Bangalore

34. Tóth D, Csépe V, Vaessen A, Blomert L (2014) 3DM-H: A diszlexia differenciáldiagnózisa. Az olvasás és helyesírás kognitív elemzése (Differential diagnosis of dyslexia. Cognitive analysis of reading and spelling), Technical Manual. Kogentum, Hungary

35. Blomert L, Vaessen A (2009) 3DM differential diagnostics for dyslexia: cognitive analysis of reading and spelling. Boom Test Publishers, Amsterdam

36. Kaufman J, Birmaher B, Brent D, Rao UMA, Flynn C, Moreci P, Williamson D, Ryan N (1997) Schedule for affective disorders and schizophrenia for schoolage children-present and lifetime version (K-SADS-PL): initial reliability and validity data. J Am Acad Child Adolesc Psychiatry 36(7):980-988 https://doi. org/10.1097/00004583-199707000-00021

37. Spence SH, Barrett PM, Turner CM (2003) Psychometric properties of the Spence Children's Anxiety Scale with young adolescents. J Anxiety Disord 17(6):605-625 https://doi.org/10.1016/S0887-6185(02)00236-0

38. Felder-Puig R, Baumgartner M, Topf R, Gadner H, Formann AK (2008) Health-related quality of life in Austrian elementary school children. J Med Care 46(4):432-439 https://doi.org/10.1097/MLR.0b013e3181648e95

39. Beitchman J, Wilson B, Johnson C, Atkinson L, Young A et al (2001) Fourteen-year follow-up of speech/language-impaired and control children: psychiatric outcome. J Am Acad Child Adolesc Psychiatry 40:75-82 https:// doi.org/10.1097/00004583-200101000-00019

40. DuPaul GJ, Gormley MJ, Laracy SD (2013) Co-morbidity of LD and ADHD: implications of DSM-V for assessment and treatment. J Learn Disabil 46(1): 43-51. https://doi.org/10.1177/2F0022219412464351

41. Al-Mamari WS, Emam MM, Al-Futaisi AM, Kazem AM (2015) Co-morbidity of learning disorders and attention deficit hyperactivity disorder in a sample of Omani schoolchildren. Sultan Qaboos Univ Med J 15(4):e528

42. Ritter FE, Baxter GD, Churchill EF (2014) Cognition: memory, attention, and learning. In: Ritter FE et al (eds) Foundations for Designing User-Centered Systems. Springer, London, pp 123-164

43. Dehn MJ (2008) Working memory and academic learning: assessment and intervention. Wiley, New Jersey

44. Dehn MJ (2011) Helping students remember: exercises and strategies to strengthen memory. Wiley, New Jersey

45. Dewitz P, Dewitz PK (2003) They can read the words, but they can't understand: refining comprehension assessment. Read Teach 56(5):422-435

46. Hughes C (2013) Executive function: development, individual differences, and clinical insights. In: Rbenstein JLR, Rakic PP (eds) Neural circuit development and function in the brain, 1st edn. Elsevier, USA

47. Nelson JM, Harwood $H$ (2011) Learning disabilities and anxiety: a metaanalysis. J Learn Disabil 44(1):3-17. https://doi.org/10.1177/ 2F0022219409359939

48. Grills-Taquechel AE, Fletcher JM, Vaughn SR, Stuebing KK (2012) Anxiety and reading difficulties in early elementary school: evidence for unidirectional-or bi-directional relations? Child Psychiatry Hum Dev 43(1):35-49 https://doi. org/10.1007/s10578-011-0246-1

49. Eysenck MW, Derakshan N, Santos R, Calvo MG (2007) Anxiety and cognitive performance: attentional control theory. J Emotion 7(2):336-353 https://doi. org/10.1037/1528-3542.7.2.336

50. Pekrun R, Goetz T, Titz W, Perry RP (2002) Academic emotions in students' self-regulated learning and achievement: a program of qualitative and quantitative research. Educ Psychol J 37(2):91-105 https://doi.org/10.1207/ S15326985EP3702_4

51. Nelson JM, Gregg N (2012) Depression and anxiety among transitioning adolescents and college students with ADHD, dyslexia, or comorbid ADHD/ dyslexia. J Atten Disord 16(3):244-254. https://doi.org/10.1177/ 2F1087054710385783

52. Owens M, Stevenson J, Hadwin JA, Norgate R (2012) Anxiety and depression in academic performance: an exploration of the mediating factors of worry and working memory. Sch Psychol Int J 33(4):433-449. https://doi.org/10.1177/2F0143034311427433

53. Selvi Y, Aydin A, Boysan M, Atli A, Agargun MY, Besiroglu L (2010) Associations between chronotype, sleep quality, suicidality, and depressive symptoms in patients with major depression and healthy controls. Chronobiol Int J 27(9-10): 1813-1828 https://doi.org/10.3109/07420528.2010.516380

54. Huc-Chabrolle M, Barthez MA, Tripi G, Barthélémy C, Bonnet-Brilhault F (2010) Psycho-cognitive and psychiatric disorders associated with developmental dyslexia: a clinical and scientific issue. J Encephale 36(2):172179 https://doi.org/10.1016/j.encep.2009.02.005

55. Smith T, Adams G (2006) The effect of comorbid AD/HD and learning disabilities on parent-reported behavioral and academic outcomes of children. Learn Disabil Q 29(2):101-112 https://doi.org/10.2307/30035538

56. Waldman ID, Rhee SH, Levy F, Hay DA (2001) Causes of the overlap among symptoms of ADHD, oppositional defiant disorder, and conduct disorder. In: Levy F, Hay DA (eds) Attention, genes, and ADHD. Brunner-Routledge, New York, pp 115-138

57. Levy F, Young DJ, Bennett KS, Martin NC, Hay DA (2013) Comorbid ADHD and mental health disorders: are these children more likely to develop reading disorders? J Atten Defic Hyperact Disord 5(1):21-28 https://doi.org/ 10.1007/s12402-012-0093-3

58. Mugnaini D, Lassi S, La Malfa G, Albertini G (2009) Internalizing correlates of dyslexia. World J Pediatr 5(4):255-264 https://doi.org/10. 1007/s12519-009-0049-7

\section{Publisher's Note}

Springer Nature remains neutral with regard to jurisdictional claims in published maps and institutional affiliations.

\section{Submit your manuscript to a SpringerOpen ${ }^{\circ}$ journal and benefit from:}

- Convenient online submission

- Rigorous peer review

- Open access: articles freely available online

- High visibility within the field

- Retaining the copyright to your article

Submit your next manuscript at $>$ springeropen.com 